\title{
Age over 46 years does not affect the pressure lowering effect of trabeculectomy in primary open angle glaucoma
}

\author{
M C Briggs, J L Jay
}

\begin{abstract}
Backgroundlaims-Previous reports have suggested that the success rate for trabeculectomy is poorer in younger age groups but these studies often have heterogeneous groups representing different types of glaucoma with variable surgical prognosis. Therefore, the relation between age and the success of trabeculectomy in the single diagnostic category of primary open angle glaucoma (POAG) without identifiable risk factors was examined for failure in the age range 46-85 years.

Methods-The records of 208 patients who had undergone a first trabeculectomy for POAG were examined retrospectively. Age ranged from 46 to 85 (mean 66.7 years). The outcome of surgery was examined at final available follow up and at 1 and 2 years after surgery. Trabeculectomy was considered a success if intraocular pressure was $\leqslant 21 \mathrm{~mm} \mathrm{Hg}$ with or without additional medical treatment ("cumulative" success) and an "absolute" success if intraocular pressure was $\leqslant 21 \mathrm{~mm} \mathrm{Hg}$ without additional medical treatment.

Results-Cumulative success for trabeculectomy was $92.3 \%$ at final follow up and $96.6 \%$ at 2 year follow up; absolute success rate was $66.3 \%$ at final follow up and $71.6 \%$ at 2 years. There was no significant trend for greater success of trabeculectomy in the older age groups (cumulative success at 2 year follow up, $\chi^{2}$ for linear trend $1.07(p=0.3)$ nor was the drop in intraocular pressure following surgery significantly greater with increasing age (analysis of variance for intraocular pressure lowering from presentation to 2 years' follow up (Kruskal-Wallis, $t=5.9$, $\mathrm{p}=0.55$ ). Patients with pseudoexfoliation were excluded from the main analysis as these patients have been shown to have a lower final intraocular pressure following trabeculectomy, a finding which was confirmed in this study.
\end{abstract}

Accepted for publication
30 September 1998

Table 1 Age and duration of follow up

\begin{tabular}{llllll}
\hline $\begin{array}{l}\text { Age group } \\
\text { (at trab) }\end{array}$ & $\begin{array}{l}\text { Number of } \\
\text { patients }\end{array}$ & $\begin{array}{l}\text { Mean age } \\
\text { (years) }\end{array}$ & $\begin{array}{l}\text { Median follow } \\
\text { up (months) }\end{array}$ & $\begin{array}{l}\text { Follow up 25th to } \\
\text { 75th percentile }\end{array}$ & $\begin{array}{l}\text { Proportion of operations } \\
\text { by training grade }\end{array}$ \\
\hline $45-50$ & 16 & 48.4 & 49.5 & $30.8-78.5$ & $50 \%$ \\
$51-55$ & 21 & 52.7 & 54 & $25-68$ & $42.9 \%$ \\
$56-60$ & 25 & 58.2 & 40 & $35-82$ & $72 \%$ \\
$61-65$ & 36 & 63.0 & 53 & $29.8-90$ & $58.3 \%$ \\
$66-70$ & 28 & 68.1 & 49 & $34.8-75.2$ & $50 \%$ \\
$71-75$ & 28 & 72.9 & 68 & $44.8-87.8$ & $60.7 \%$ \\
$76-80$ & 30 & 78.2 & 53 & $30-79$ & $60 \%$ \\
$81-85$ & 24 & 82.5 & 36 & $27-63$ & $83.3 \%$ \\
All ages & 208 & 66.7 & 53.5 & $31-80$ & $60.1 \%$ \\
\hline
\end{tabular}

Conclusion-This study demonstrates that in the age range $46-85$ years there is no demonstrable relation between age at the time of surgery and success of trabeculectomy in POAG

(Br f Ophthalmol 1999;83:280-284)

Several factors have been shown to influence the success of trabeculectomy in lowering intraocular pressure. Among these are the type of glaucoma, ${ }^{1-3}$ ethnic origin, ${ }^{45}$ previous surgery, ${ }^{67}$ and previous topical antiglaucoma medication. ${ }^{89}$ Several previous reports have also examined the relation between the success of surgery and age..$^{6-12}$ These studies often suggest a lower success rate for drainage surgery in younger age groups in various types of glaucoma ${ }^{7-12}$ and in patients with primary open angle glaucoma (POAG) alone ${ }^{6}$ over both a wide range of ages ${ }^{6-11}$ and in groups of young patients, ${ }^{1012}$ but close scrutiny suggests that coincidental risk factors for failure were often present in these reports. Two of these reports concerned patients considerably younger than those routinely undergoing glaucoma surgery ${ }^{10}{ }^{12}$; however, the aim of the present study was to determine whether any effect of age on outcome of trabeculectomy was present across the age range more commonly encountered in glaucoma surgery-that is, 46-85 years. We have examined the relation between age at the time of surgery as an isolated variable and the success of trabeculectomy as determined by intraocular pressure at follow up in a group of patients undergoing a first trabeculectomy for POAG. The effect of pseudoexfoliation on surgical result was examined separately because of the reported lower pressure following trabeculectomy in such eyes. ${ }^{13}$

\section{Patients and methods}

The operating theatre log book in the Tennent Institute was used to identify patients who had undergone trabeculectomy during the period January 1986 to December 1994. Notes were then obtained for each patient and those who had undergone trabeculectomy for POAG were studied. Patients with other forms of glaucoma, those who had undergone previous surgery, and those in whom antimetabolites had been used were excluded. For those patients who had undergone bilateral surgery the first eye to be operated on was used as the study eye. In those cases where bilateral surgery was performed simultaneously, and it was impossible to determine from the notes which eye was operated on first, the eye to be studied was chosen at random. 
Table 2 Indication for trabeculectomy plus median duration of medical treatment before trabeculectomy. There may be more than one indication for each patient

\begin{tabular}{|c|c|c|c|c|c|c|c|}
\hline Age group & $\begin{array}{l}\text { Primary } \\
\text { trabeculectomy }\end{array}$ & $\begin{array}{l}\text { Increasing visual } \\
\text { field loss }\end{array}$ & $\begin{array}{l}\text { Uncontrolled } \\
\text { intraocular pressure }\end{array}$ & $\begin{array}{l}\text { Intolerance of } \\
\text { medical treatment }\end{array}$ & $\begin{array}{l}\text { Increasing optic } \\
\text { disc cupping }\end{array}$ & $\begin{array}{l}\text { Total number } \\
\text { of patients }\end{array}$ & $\begin{array}{l}\text { Median duration of preoperative medical } \\
\text { treatment (25th-75th percentile) (months) }\end{array}$ \\
\hline $46-50$ & 4 & 2 & 9 & 2 & 0 & 16 & $3(1-20.5)$ \\
\hline $51-55$ & 3 & 9 & 12 & 1 & 2 & 21 & $15(3-36)$ \\
\hline $56-60$ & 6 & 9 & 14 & 0 & 6 & 25 & $9(2-40)$ \\
\hline $61-65$ & 6 & 10 & 20 & 1 & 3 & 36 & $29.5(8.5-74.2)$ \\
\hline $66-70$ & 5 & 10 & 18 & 0 & 2 & 28 & $10.5(3-50)$ \\
\hline $71-75$ & 5 & 9 & 19 & 0 & 2 & 28 & $12(3.8-24.2)$ \\
\hline $76-80$ & 7 & 14 & 17 & 0 & 2 & 30 & $17(2.2-62)$ \\
\hline $81-85$ & 2 & 10 & 15 & 1 & 0 & 24 & $12(6.8-48.8)$ \\
\hline
\end{tabular}

Operating technique and postoperative care were not strictly standardised but generally followed the technique described previously. ${ }^{14}$ Operations were performed both by consultants and by those in the training grades. Previous studies have shown that the outcome is similar when the results of trabeculectomies performed by junior surgeons is compared with those achieved by more experienced practitioners. ${ }^{15-16}$

The following preoperative details were obtained from the case notes: type of glaucoma, age at trabeculectomy, intraocular pressure at diagnosis, the intraocular pressure at the time the decision was made to proceed to trabeculectomy, the duration of medical treatment before trabeculectomy, and the indication for surgery. In addition, the severity of glaucomatous visual field loss at the time of trabeculectomy was estimated using a simple grading system. ${ }^{17}$

The following postoperative details were obtained: intraocular pressure at final follow up, at 12 months, and at 24 months; which antiglaucoma treatment was being used at each of these intervals; the date of final follow up; and the reason follow up ceased. The final follow up was taken as the most recent entry in the notes or the final visit before either further glaucoma surgery or cataract surgery. Those in whom final follow up was at less than 12 months postoperatively were excluded. No patients had further glaucoma surgery before the second anniversary of their trabeculectomy, and those patients whose follow up ended before the second anniversary were excluded from analysis for that date.

In order to provide a large number of groups so that any trend in success rate would be identifiable patients were divided into groups by age at 5 year intervals for the analysis. The youngest age group studied was 46-50 years and the oldest, 81-85 years. There were relatively few trabeculectomies performed in the age groups at either end of the range and many more in those in between. Hospital case records were therefore obtained for all patients in the lowest three age groups and for the

Table 3 Success rate at 1 year follow up

\begin{tabular}{lllll}
\hline Age group & Total & $\begin{array}{l}\text { Success } \leqslant 21 \mathrm{~mm} \mathrm{Hg} \\
\text { (no treatment) }\end{array}$ & $\begin{array}{l}\text { Relative success } \leqslant 21 \mathrm{~mm} \\
\text { Hg (with treatment) }\end{array}$ & $\begin{array}{l}\text { Failure } \\
>21 \mathrm{~mm} \mathrm{Hg}\end{array}$ \\
\hline $45-50$ & 16 & $12(75 \%)$ & $3(18.8 \%)$ & $1(6.2 \%)$ \\
$51-55$ & 21 & $18(85.7 \%)$ & $3(14.3 \%)$ & 0 \\
$56-60$ & 25 & $18(72.0 \%)$ & $5(20.0 \%)$ & $2(8.0 \%)$ \\
$61-65$ & 36 & $28(77.8 \%)$ & $5(13.9 \%)$ & $3(8.3 \%)$ \\
$66-70$ & 28 & $21(75.0 \%)$ & $5(17.9 \%)$ & $2(7.1 \%)$ \\
$71-75$ & 27 & $20(74.1 \%)$ & $6(22.2 \%)$ & $1(3.7 \%)$ \\
$76-80$ & 30 & $26(86.7 \%)$ & $4(13.3 \%)$ & 0 \\
$81-85$ & 24 & $20(83.3 \%)$ & $3(12.5 \%)$ & $1(4.2 \%)$ \\
All ages & 207 & $163(78.7 \%)$ & $34(16.4 \%)$ & $10(4.8 \%)$ \\
\hline
\end{tabular}

uppermost group. For the other groups lists of potentially eligible patients were made in random order from the theatre log and these notes requested from the hospital record library using hospital number alone. Once sufficient notes had been obtained to make up groups of comparable size no further notes were requested.

Several outcome criteria were studied. "Absolute success" of trabeculectomy was defined as intraocular pressure of $21 \mathrm{~mm} \mathrm{Hg}$ or less on no treatment and "relative success" as pressure of $21 \mathrm{~mm} \mathrm{Hg}$ or less with either topical or systemic treatment. The addition of these two groups gave "cumulative success". Intraocular pressure of more than $21 \mathrm{~mm} \mathrm{Hg}$ regardless of treatment was interpreted as failure to control intraocular pressure. In addition, the extent of intraocular pressure lowering was calculated by using both the difference in intraocular pressure from diagnosis to follow up and also the difference from the time the decision was made to proceed to trabeculectomy to follow up. In the case of this latter calculation some patients were on medical treatment when the decision was made to proceed to surgery while others who underwent primary trabeculectomy, for example, were not. The intraocular pressure at follow up was also taken as a measure of outcome. Statistical analysis was performed using Arcus PRO-STAT software.

\section{Results}

Information was available on 208 patients. All patients were white. The number of patients in each age group, their mean ages, and follow up are shown in Table 1. The proportion of operations performed by those in training grades is also shown in Table 1, the remainder were performed by consultant surgeons. The range of follow up for individual ages was 12-175 months and median follow up for the different age groups ranged from 36 to 68 months. Overall median duration of medical treatment before trabeculectomy was 14 months with medians for each group ranging from 3 to 29.5, there was no significant difference for duration of medical treatment (Kruskal-Wallis, $t=9.55, \mathrm{p}=0.22$ ). Indications for trabeculectomy and duration of medical treatment are shown in Table 2 .

Cumulative success rate (intraocular pressure $\leqslant 21 \mathrm{~mm} \mathrm{Hg}$ with or without medication) for trabeculectomy was $92.3 \%$ and absolute success rate, $66.3 \%$ (intraocular pressure $\leqslant 21$ $\mathrm{mm} \mathrm{Hg}$ without medication) at final follow up. In view of this wide range of intervals to final follow up we have restricted further analysis of the data to outcomes at 1 and 2 years' follow 
Table 4 Success rate at 2 year follow up

\begin{tabular}{lllll}
\hline Age group & Total & $\begin{array}{l}\text { Success } \leqslant 21 \mathrm{~mm} \mathrm{Hg} \\
\text { (no treatment) }\end{array}$ & $\begin{array}{l}\text { Relative success } \leqslant 21 \mathrm{~mm} \\
\text { Hg (with treatment) }\end{array}$ & $\begin{array}{l}\text { Failure } \\
>21 \mathrm{~mm} \mathrm{Hg}\end{array}$ \\
\hline $45-50$ & 14 & $11(78.6 \%)$ & $3(28.4 \%)$ & 0 \\
$51-55$ & 17 & $9(52.9 \%)$ & $6(35.3 \%)$ & $2(11.8 \%)$ \\
$56-60$ & 21 & $15(71.4 \%)$ & $6(28.6 \%)$ & 0 \\
$61-65$ & 31 & $21(67.7 \%)$ & $9(29.0 \%)$ & $1(3.2 \%)$ \\
$66-70$ & 27 & $19(70.4 \%)$ & $5(18.5 \%)$ & $3(11.1 \%)$ \\
$71-75$ & 24 & $15(62.5 \%)$ & $9(37.5 \%)$ & 0 \\
$76-80$ & 23 & $20(87.0 \%)$ & $3(13.0 \%)$ & 0 \\
$81-85$ & 19 & $16(84.2 \%)$ & $3(15.8 \%)$ & 0 \\
All ages & 176 & $126(71.6 \%)$ & $44(25.0 \%)$ & $6(3.4 \%)$ \\
\hline
\end{tabular}

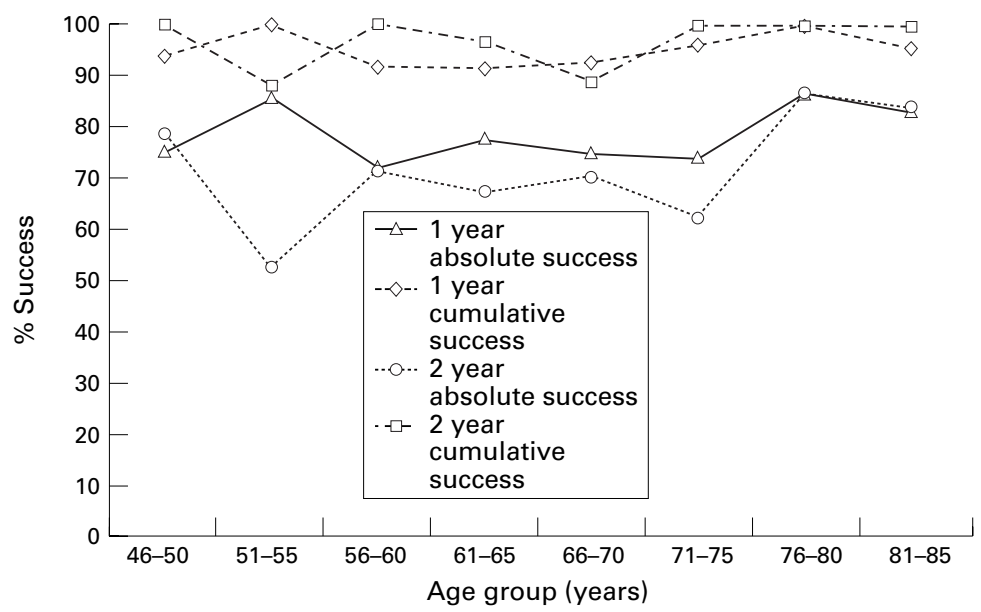

Figure 1 Illustration of absolute and cumulative success rates at 1 and 2 year follow up.

Table 5 Visual field loss at the time of trabeculectomy

\begin{tabular}{llllll}
\hline $\begin{array}{l}\text { Age } \\
\text { group }\end{array}$ & Total & $\begin{array}{l}\text { Range of grade of } \\
\text { visual field loss }\end{array}$ & $\begin{array}{l}\text { Mean grade of } \\
\text { visual field loss }\end{array}$ & $\begin{array}{l}\text { Median grade of } \\
\text { visual field loss }\end{array}$ & $\begin{array}{l}\text { Visual field loss } \\
\text { 25th-75th percentile }\end{array}$ \\
\hline $45-50$ & 16 & $0-4$ & 1.9 & 2 & $1-3$ \\
$51-55$ & 21 & $1-5$ & 2.3 & 2 & $1-3.2$ \\
$56-60$ & 25 & $0-5$ & 2.6 & 2 & $1-4$ \\
$61-65$ & 36 & $0-5$ & 2.5 & 2 & $1-4$ \\
$66-70$ & 28 & $0-5$ & 2.6 & 4 & $1-4$ \\
$71-75$ & 28 & $1-5$ & 3.0 & 4 & $1-4$ \\
$76-80$ & 30 & $1-5$ & 3.4 & 3 & $1-4$ \\
$81-85$ & 24 & $0-5$ & 3.2 & 3 & $2-4$ \\
All ages & 208 & $0-5$ & 2.7 & 3.0 & $1-4$ \\
\hline
\end{tabular}

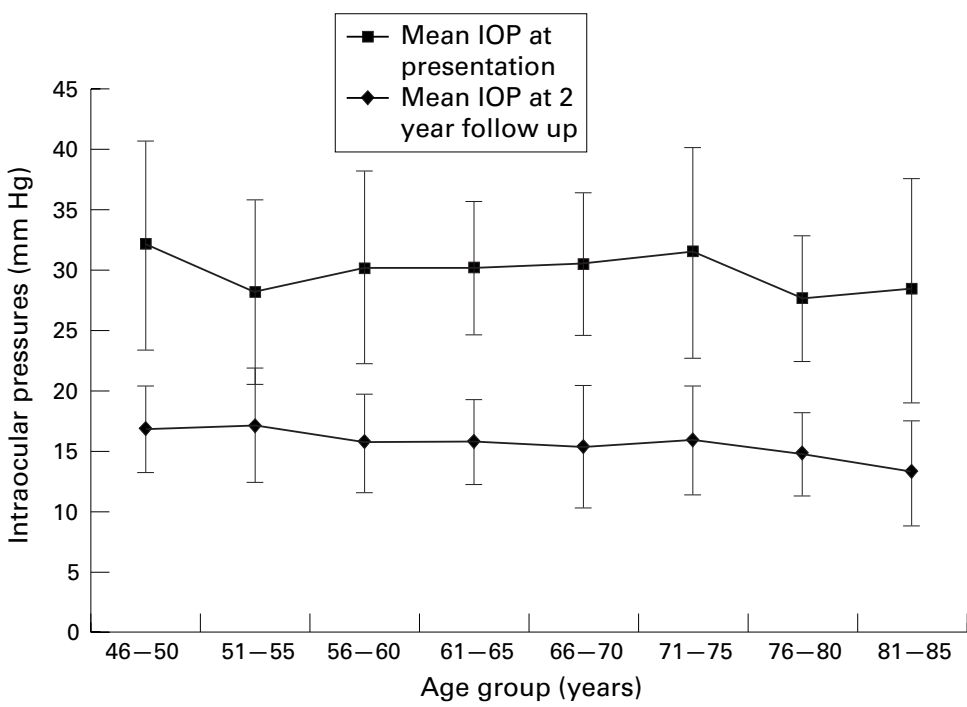

Figure 2 Mean intraocular pressure at presentation and at 2 year follow up for each age group. up. Rates of success and relative success at 1 and 2 year follow up are shown in Tables 3 and 4. Figure 1 is a line graph illustrating absolute and cumulative success rates at 1 and 2 years' follow up. This suggests a trend for increasing absolute success at 2 years' follow up in the patients with age greater than 75 years of age which did not extend into the younger age groups. Analysis of the success rates using contingency table analysis and the $\chi^{2}$ test, however, failed to demonstrate a linear trend for any of the four series of data. The $\chi^{2}$ test for linear trend was as follows: for absolute success at 2 years, $2.31(\mathrm{p}=0.13)$, for cumulative success at 2 years, $1.07(\mathrm{p}=0.3)$. For absolute success at 1 year, $0.47(p=0.5)$, for cumulative success at 1 year, $0.45(\mathrm{p}=0.5)$.

Extent of visual field loss at the time of trabeculectomy varied from grade 0 to 5 with the mean for each group ranging from 1.9 to 3.4 and the median 2 to 4 (see Table 5), there was significantly greater field loss in the older age groups (Kruskal-Wallis $t=18.6, \mathrm{p}<0.01$ ). Results were therefore reanalysed to exclude those with field loss of greater than 3 giving a range of means of 1.4 to $2.4 \quad(n=124$, no significant difference, Kruskal-Wallis $t=10.26$, $\mathrm{p}=0.17)$. This did not affect the significance of any trend for cumulative success at $1\left(\chi^{2}\right.$ for linear trend $=1.4, \mathrm{p}=0.2)$ or 2 year follow up $\left(\chi^{2}\right.$ for linear trend $=0.29, p=0.6$ ).

Dividing the series of patients into two groups - that is, those younger than 61 years and those older than 61 years, similarly shows no significant difference in outcome at 2 year follow up: $\chi^{2}$ with Yates's correction for cumulative success is $0, \mathrm{p}=1.0$ (95\% CI 0.15 to 4.7$)$ and for absolute success $\chi^{2}$ with Yates's correction is $0.40, \mathrm{p}=0.5$ (95\% CI 0.37 to 1.5$)$.

The intraocular pressure lowering effect was also examined. Analysis of variance (KruskalWallis) shows no difference for intraocular pressure lowering for the series of age groups from presentation to 2 years' follow up (Kruskal-Wallis, $t=5.9, \mathrm{p}=0.55)$ and from listing for trabeculectomy to 2 years' follow up $(t=5.1, \mathrm{p}=0.65)$.

Additionally we analysed the follow up intraocular pressure levels. Figure 2 shows mean intraocular pressure at presentation and at 2 year follow up for each age group. There is a trend for a lower follow up intraocular pressure with increasing age; however, analysis of variance (Kruskal-Wallis) demonstrates that there is no significant variation between individual groups $(t=11.8, \mathrm{p}=0.11)$.

There were 27 cases of pseudoexfoliation which were excluded from the main analysis. These patients were found in the upper six age groups as follows: age 56-60, five cases; age 61-65, four cases; age 66-70, seven cases; age $71-75$, three cases; age 76-80, four cases; and age $81-85$, four cases. Absolute and cumulative successes for this group were respectively $85.2 \%$ and $96.3 \%$ at 1 year follow up and $69.6 \%$ and $100 \%$ at 2 year follow up. Repeat analysis was performed with data from this group included. The result of this analysis was a significant variance for intraocular pressure at 2 year follow up (Kruskal-Wallis, $t=14.4$, 
$\mathrm{p}=0.04)$. Despite this the reduction in intraocular pressure between presentation and 2 year follow up did not vary significantly with the inclusion of patients with pseudoexfoliation (Kruskal-Wallis, $t=5.9, \mathrm{p}=0.6$ ).

\section{Discussion}

Previous studies have cited success rates for all age groups of $87 \%$ ( $\leqslant 21$ with or without medication, follow up: at least 1 year $),{ }^{18} 77.5 \%(<21$ with or without medication, follow up: 3 months to 5 years), ${ }^{6}$ and $87 \%(<21 \mathrm{~mm} \mathrm{Hg}$ with or without medication, follow up 7 years $)^{19}$ for trabeculectomy in chronic open angle glaucoma, and $76 \%$ (<20 $\mathrm{mm} \mathrm{Hg}$ with or without medication, mean follow up 48 months $)^{20}$ in all types of glaucoma. In our study we have examined the outcome of trabeculectomy across the age range in which the operation is commonly undertaken and the success rates are comparable with the previous studies which were not age specific: the corresponding "cumulative" success rate (intraocular pressure $\leqslant 21 \mathrm{~mm} \mathrm{Hg}$ with or without medication) for trabeculectomy in our series is $92.3 \%$ and the absolute success rate, $66.3 \%$ (intraocular pressure $\leqslant 21 \mathrm{~mm} \mathrm{Hg}$ without medication).

In contrast, one study examining the success rate for trabeculectomy in young patients quoted a poorer success rate of $54.4 \%$ (intraocular pressure $\leqslant 21 \mathrm{~mm} \mathrm{Hg}$ without antiglaucoma medication, mean age 33.3 years, mean follow up 36.7 months) for all glaucoma. ${ }^{12}$ This report was not restricted to one diagnostic group and, in addition, patients often had other risk factors for failure. They concluded that it was not age itself which led to the reduced success rate but these other risk factors which occur more frequently in younger patients. A different study quoted a "complete" success rate of $38.5 \%$ (intraocular pressure $\leqslant 21 \mathrm{~mm} \mathrm{Hg}$ without antiglaucoma medication, mean age 38 years, mean follow up 35 months) for primary (open angle or angle closure) glaucoma and a cumulative success rate of $74 \%$ (intraocular pressure $\leqslant 21 \mathrm{~mm} \mathrm{Hg}$ with or without medication or intraocular pressure $22-25 \mathrm{~mm} \mathrm{Hg}$ without medication). ${ }^{10}$ This rate of success approaches that for all age groups quoted in some studies. ${ }^{7-20}$ A further study compared success rates in those younger than 60 years of age with those older and demonstrated an increase in the probability of failure of trabeculectomy (intraocular pressure $<21 \mathrm{~mm} \mathrm{Hg}$ with or without medication) in POAG in the younger group, although this did not reach statistical significance. ${ }^{6}$

There is therefore no convincing evidence to date that age alone is a risk factor for reduced success in trabeculectomy for POAG. In our study we have attempted to reduce the effect of other factors which influence success of surgery by excluding patients with a diagnosis other than POAG plus those patients who had had previous surgery. We also excluded patients with pseudoexfoliation glaucoma as these patients tend to have a higher initial intraocular pressure and a lower pressure following surgery. ${ }^{13}$ There was a trend for more severe glaucoma as evidenced by the higher grade of visual field loss in the older patients; however, reducing the influence of this variable by excluding those with field loss of greater than " 3 " did not alter the cumulative success rates at final follow up. In addition, the duration of medical treatment before trabeculectomy was relatively even across the eight groups. Indications for trabeculectomy were similar for all groups. In this study the numbers of patients in each age group, particularly those at either end of the range, were relatively small. The power to detect a trend for a lower success rate in younger patients compared with those over the age of 75 years is limited but on the basis of our results any possible trend would be a relatively weak one and we think that it would be unlikely to be enough to justify a different approach to the management of younger patients in the absence of more definite risk factors for failure of conventional drainage surgery.

As this study was restricted to patients in the age range $46-85$ years, the results do not allow us to draw any conclusions regarding success of trabeculectomy in patients below the age of 46 years.

The success rates for the patients grouped by half decade show wide variation but there is no demonstrable trend in the success rate with increasing age, nor is there any difference in success rate when those younger than 61 years are compared with those older. There is also no significant effect of age on the drop in intraocular pressure following trabeculectomy. There is a trend which does not reach significance for the final intraocular pressure to be lower in the older patients in the age range studied which is not simply a reflection of lower intraocular pressures before surgery. With the inclusion of patients with pseudoexfoliation found only in the upper six age groups there is a significant trend for lower pressure as age increases which would appear to confirm a previous report that final intraocular pressure is lower following trabeculectomy in this particular form of open angle glaucoma.

This study suggests that there is no demonstrable effect of age in the range $46-85$ years on the outcome of trabeculectomy for a homogeneous group with POAG without additional risk factors for failure and excluding those patients with pseudoexfoliation.

1 Jones NP. Glaucoma in Fuch's heterochromic uveitis: aetiology, management and outcome. Eye 1991;5:662-7.

2 Hoskins HD, Hetherington J Jr, Schaffer RN. Surgical management of the inflammatory glaucomas. Perspect Ophthalmol $1977 ; 1: 173-81$.

3 Allen RC, Bellows AR, Hutchinson BT, et al. Filtration surAllen RC, Bellows AR, Hutchinson BT, et al. Filtration sur-
gery in the treatment of neovascular glaucoma. Ophthalmolgery in the treatment of
ogy 1982;89:1181-7.

4 Miller RD, Barber JC. Trabeculectomy in black patients. Miller RD, Barber JC. Trabeculect
Ophthalmic Surg 1981;12:46-50.

5 Shingleton BJ, Distler JA, Baker BH. Filtration surgery in black patients: early results in a West Indian population. Ophthalmic Surg 1987;18:195-9.

6 Inaba Z. Long-term results of trabeculectomy in the Japanese: an analysis by life-table method. Fpn $\mathcal{F}$ Ophthalmol 1982;26:361-373.

7 Schwartz AL, Anderson DR. Trabecular surgery. Arch Ophthalmol 1974; 92:134-8.

8 Lavin MJ, Wormald RPL, Migdal CS, et al. The influence of prior therapy on the success of trabeculectomy. Arch Ophthalmol 1990;108:1543-8.

9 Broadway DC, Grierson I, O’Brien, et al. Adverse effects of topical antiglaucoma medication. II The outcome of filtration surgery. Arch Ophthalmol 1994;112:1446-54.

10 Gressel MG, Heuer DK, Parrish RK. Trabeculectomy in young patients. Ophthalmology $1984 ; 91: 1242-6$.

11 Jerndal T, Lundstrom M. 330 Trabeculectomies. A long time study (3-51/2years). Acta Ophthalmol 1980;58:947-56. 
12 Sturmer J, Broadway DC, Hitchings RA. Young patient trabeculectomy. Assessment of risk factors for failure. $O p h$ 9.100:928-39.

13 Konstas AG, Jay JL, Marshall GE, et al. Prevalence, diagnostic features, and response to trabeculectomy in exfoliation glaucoma. Ophthalmology 1993;100:619-27.

14 Konstas AGP, Jay JL. Modification of trabeculectomy to avoid postoperative hyphaema. The 'guarded anterior fistula' operation. Br $\mathcal{F}$ Ophthalmol 1992;76:353-7.

15 Morrell AJ, Searle AET, O'Neill EC. Trabeculectomy as an
introduction to intraocular surgery in an ophthalmic training program. Ophthalmic Surg 1989;20:557-60.
16 Murray SB, Jay JL. Trabeculectomy: its role in the management of glaucoma. Trans Ophthalmol Soc UK 1979;99:492-4

7 Jay JL. Rational choice of therapy in primary open angle glaucoma. Eye 1992;6:243-7.

18 Ridgway AE. Trabeculectomy. Br f Ophthalmol 1974;58: 680-6.

9 Wilson PW. Trabeculectomy: long-term follow-up. $\mathrm{Br} F$ Ophthalmol 1977;61:535-8.

20 Lamping KA, Bellows AR, Hutchinson BT, et al. Long-term evaluation of initial filtration surgery. Ophthalmology 1986; 93:91-101. 